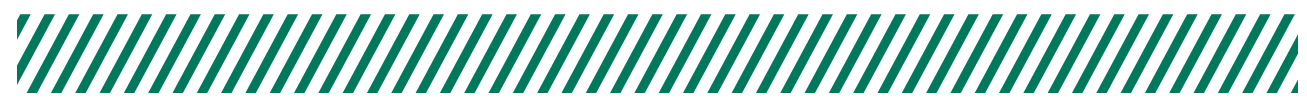

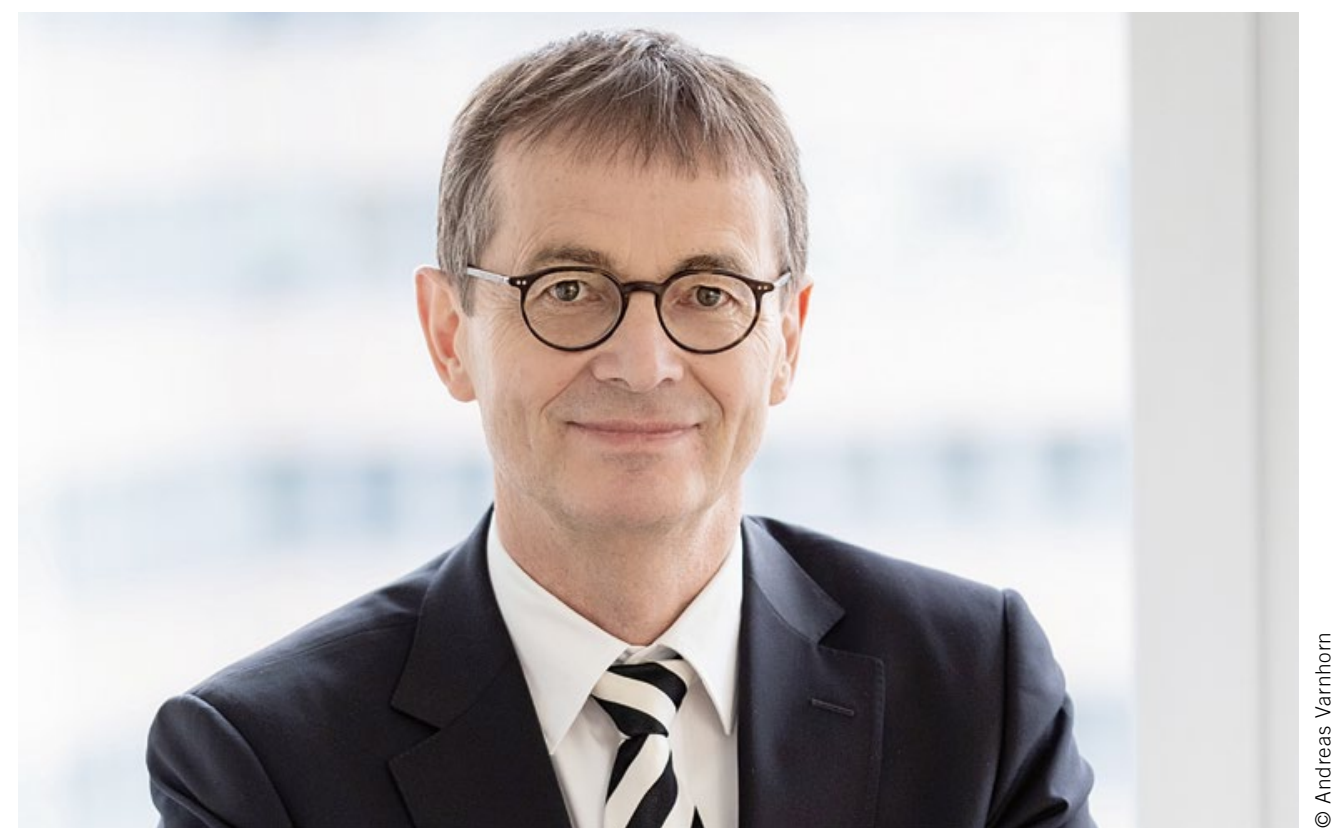

Dr. Bernd Scherer

Geschäftsführer des

Fachverbands Landtechnik

im VDMA in Frankfurt

\title{
40 \% weniger Diesel - dank kühlem Kopf statt bleiernem Gasfuß
}

Wer viel Auto fährt, kennt ihn nur zu gut - den trügerischen Glauben, mit mehr Tempo schneller anzukommen. Meist ist es eine Illusion, denn der flotte Gasfuß sorgt selten für mehr als eine ordentliche Rechnung an der nächsten Tankstelle. Ähnlich und doch ganz anders sieht es auf Äckern, Feldwegen und Landstraßen aus, wo Landmaschinen und Traktoren im rauen Arbeits- und Transporteinsatz unterwegs sind. Auch hier spielt der Fahrer eine zentrale Rolle, wenn es darum geht, klimafreundliche Prozesse zu gewährleisten. Mit dem Unterschied jedoch, dass in der Landwirtschaft nicht bloß Kilometer gemacht, sondern vor allem Erträge generiert werden.

In einem vom Bundeslandwirtschaftsministerium mit Finanzmitteln geförderten Forschungsprojekt zur Kraftstoffeffizienz in der Agrartechnik haben Wissenschaft, Industrie und Branchenverbände in den zurückliegenden drei Jahren den kraftstoffbezogenen $\mathrm{CO}_{2}$-Fußabdruck in der Landwirtschaft erforscht. Folgerichtig stand dabei der landtechnische Dieselbedarf in Relation zum tatsächlichen Ertrag auf dem Acker im Fokus. Jetzt liegen die Ergebnisse vor. Und sie zeigen, dass sich in der Agrartechnik so einiges bewegt: Seit 1990, dem Beginn des Untersuchungszeitraums, hat sich der Dieselbedarf für die Erzeugung $1 \mathrm{t}$ Weizen um bis zu $30 \%$ reduziert - bis 2030 dürften es in der Maximalbetrachtung sogar $40 \%$ sein.

Was sagt uns das? Zum einen, dass die Landwirtschaft heterogen ist, dass es auf Verfahren und Böden, auf Klima- und Vegeta- tionszonen ankommt, will man den landwirtschaftlichen Prozess vernünftig beurteilen. Zum anderen, dass Landtechnik, der wichtigste Enabler moderner Landwirtschaft, ganz wesentlich dazu beiträgt, Klimapotenziale zu heben. Potenziale, die mit Blick auf die einzelne Maschine und deren Motor sicher bereits die Grenze des physikalisch Machbaren erreicht haben, in einer dezidierten Prozessbetrachtung jedoch noch längst nicht ausgeschöpft sind. Wer etwa seine Logistikkette optimiert, auf minutengenaue Taktung, intelligentes Motormanagement und großen Durchsatz achtet, kann mehr mit weniger produzieren: mehr Lebensmittel mit weniger Dieseleinsatz. Schon heute sind, um eine pointierte Beispielrechnung aus dem Projekt zu zitieren, 16.000 Brötchen aus 11 Diesel herauszuholen.

Hinzu kommt der schon erwähnte Fahrer. Ihn effektiv zu schulen und für ein kluges Monitoring zunehmend automatisierter Abläufe fit zu machen, ist Aufgabe der Industrie und ihrer Handelspartner. Innovative Technik, die all das leistet, mit einem starken Push in den Markt zu bringen, ist aber auch eine Frage adäquater politischer Rahmenbedingungen: Steuerliche Investitionsförderung, attraktive Boni für klimaneutral wirtschaftende Bauern sowie ein bewusst technologieoffener Ansatz, der alternative Kraftstoffe und intelligente Prozesslösungen ebenso im Blick hat wie Elektromobilität und Brennstoffzelle, sind dafür der richtige Ansatz. Wenn uns das gelingt, hat der kühle Kopf nicht nur über den bleiernen Gasfuß gesiegt. 